\title{
A Scheme for Measuring the Neutrino Rest Mass from the $\beta$-Decay of Stored Tritium Atoms Using a Solenoid Retardation Spectrometer
}

\author{
H. Backe. J. Bonn. Th. Eóling, H. Fischer, A Hermannı, P. Leiderer, Th, Loeken, R. B. Moore, A. Osipowicz, \\ E. W. Olten and A. Picard
}

Instilut für Physik, Johannes Gulenberg-Universilâst Maınz D-6500 Mainz. Fed. Rep. of Germany', and "Foster Radiation Laboratory. McGill Univcrsily Montreal, Canada

Received Ociober 20, 1987: aicipied January 15. 1988

\begin{abstract}
A new lype of electron spectromeler is under construction at Mainz Univer. sily lhal allows a nicisuremenl of the $\beta$-specirum of Iriliun with high resolution and iransmission in order to deteriline the neuirino resi mass. di consisls of a source thal contuins alomic Iritium, lrapped in a high magnelic field. and a solenoid relarding specirometer
\end{abstract}

\section{Introduction}

The question of a finile neutrino mass has penetrated in recent ycars almost any fold of physics. It concerns the fundamental conccpts of elementary particle physics as well as thosc of astrophysics. Much more spread. even, is the experimental incerest in measuring the neutrino mass. The greal number of different altempls may be grouped into two classcs: (I) direct mass measurement from weak decay specIra; (2) indirecl measurement from (a) v-oscillations and (b) neutrino-less double $\beta$-decay. Our experiment, belonging 10 !he first troup, addresses itself in particular 10 the classical problem of determining the $\bar{\nu}_{\mathrm{c}}$-mass (ron) the $\beta$-decay spectrum of trillum near its endpoint al $18.6 \mathrm{keV}$. There, it is convemently expressed in terms of the dimension-less quantity,

$c=\left(Q_{0}-E\right) / m_{\omega}$.

i.e., the difference belween the total decay energy $Q_{0}$ and the electron energy $E$ in units of an assumed $\bar{v}_{c}$-mass $m_{v}$. The differential decay rate near the endpoint is then approximately given by

$$
\begin{aligned}
\mathrm{d} R(\varepsilon)= & S(\varepsilon) \mathrm{d} \varepsilon \sim 1 \times 10^{-: 1} R\left(m_{\ldots}, e V\right)^{\prime} \\
& \times\left(c \sqrt{\varepsilon^{2}-1}\right) \mathrm{d} \varepsilon, \quad c>1 .
\end{aligned}
$$

where $R$ is the lolal decay rale and $m_{0}$ is laken in electron volis. The funcion in brackets approaches the limil $\varepsilon^{2}-\frac{1}{2}$ for $\varepsilon \gg 1$. I is to be replaced by $\varepsilon^{z}$ for all $\varepsilon>0$ if the neulrino mass is in lacl zero. The significance of a possibie $\bar{v}_{\mathrm{c}}$-mass in $\mathrm{d} R(\varepsilon)$ is practically limited to the range $\varepsilon \leqslant 3$ which contains a fracisonal decay rate of only

$$
\Delta R(c \leqslant 3), R \sim 10^{-`}\left(m_{\llcorner}, \mathrm{eV}\right)^{\prime} \text {. }
$$

For larger $c$ the $\bar{v}_{c}$-mass causes a small, but constant ofisct of the spectrum which is gelling lost in the flucluations of the rapidly increasing couni rate

Besides the obvious count sate problem the experiment faces Ivo more basic difficulict: (1) The decerioration of the endpoint spectrum by final slate interaction in a solid target; (2) the resolution of the $\beta$-spectrometer which preferably should resolve the significant part of the spectrum (2) as well as the final state effects. In experiments, using iraditional magnetic spectrometers, the two latter problems are coupled to the count rate problem by the unfortunate circumstance that a higher resolution of the instruments can be gained only on cost of their transmission. The difficulty of anaiyzing endpoint spectra which have a debalable struclure with respccl to the final state effecis and which have been measured wilh limited stalistics and resolucion only, has led to the present controversy in the literature, where onc group insists on a finilc mass [I]

$17 \mathrm{eV} \leqslant m_{u_{\mathrm{e}}} \leqslant 40 \mathrm{eV}$

whereas its strongest opponent quotes a null resuli [2]

$m_{\nu_{e}} \leqslant 18 \mathrm{eV} \quad(95 \%$ c.l. $)$

A recent atlempt to avoid the prohlem of speciral deteriora. tion in a solid by use of a gascous Irilium Larget yielded a value of [3]

$m_{\mathrm{c}, \mathrm{z}} \leqslant 26.8 \mathrm{eV} \quad(95 \%$ c.1.).

It corroborates the result of $\mathrm{Re}$ [. [2] but still faces the problem of statistics in view of the small transmission of the spectrometer and the rather limited source strcngth.

The experimental scheme described in this paper tries 10 allack the three basic problems of spectral deterioration. Iow transmission and limiled resolution by a completely dificrent approdach. First ideas in this direcion were scimulated by the successful experiments 10 store samples of about $10^{16}$ spinpolarized ' $\mathrm{H}$-atoms in a magnetic trap al low' temperature 14. 5] which might solve (he source problem when applied 10 " $\mathrm{H}$. Thunking the casc over, il lurned out that the trapping magncl might also form the basic element of an almost ideal specerometcr as described below. While preparing this experiment the same idea has been published by Lobashev el al. [6].

\section{Principle of a source of trapped spin-polarized ${ }^{3} \mathrm{H}$-atoms}

The alomic bydrogen trap mentioned in the introduction rollows a hybrid (rapping scheme (compare rig. I. Jeft side). Axial confinement is achieved by the Stern-Gerlach potential of an inhomogenenus magnelic field of 8-10 Tesla central strength. II slores hydrogen aloms with negative electron spin projection at thormal energics nol cxceeding $\sim 1$ Kelvin. Those with positive spin projection are expelled from the trap. Radial confincment is provided by a cylinder covered 


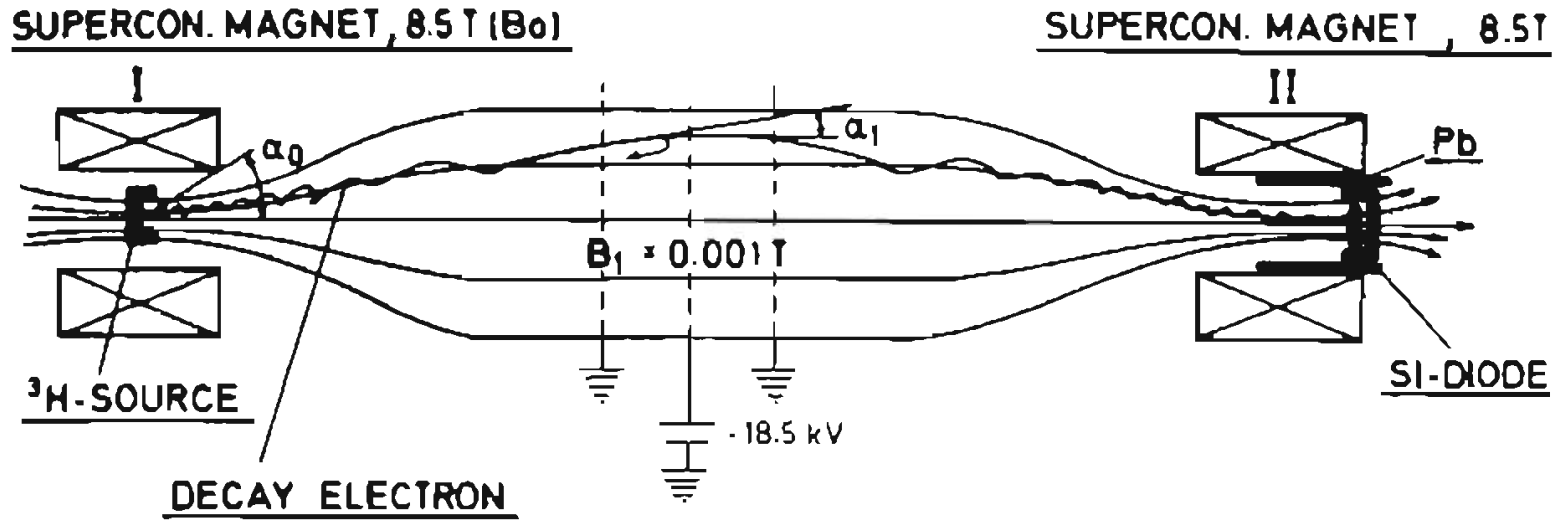

Fix. J. Pnnciple of a solenoid retardation spectrometer for analyzing the endpoint spoctnum of the $\beta$-decay from a mugnericuily crapped atomic tritium source. Lefl: T-contsiner covered with suprafiuid He and placed in the centse of an inhomogeneous $8 \mathrm{~T}$ Geld. Middle. Electrostatic fitter placed in a weik magnclic field of about $10^{-} \cdot \mathrm{T}$. Right. Second $8 \mathrm{~T}$ field reconcentrating the fux of transmitted $\beta$-particles onto (he delector.

with a superfluid He film on which atomic hydrogen will not condense ai any temperalure. Thus the atoms could only be lost by recombination. This does nol occur in a spin-polarized gas. however, since the triple: states of the $\mathrm{H}_{2}$-molecule are unbound. This way, it was possible to store hydrogen atoms at densities of $10^{16} / \mathrm{cm}^{3}$ for limes of hours [7.8]. Applied to tritium this scheme would obviously provide an ideal source for measuring the endpoint spectrum. However. physical chemistry of tritium at low temperatures is distinclly different from that of hydrogen due to the reduced zero point motion of the former. Calculations indicate that atomic tritium is probably still unbound by a few $\mathrm{K}$ in bulk liquid He with respect 10 the vacuum state. But the calculations also show the existence of bound surface states for tritium into which most of atoms may condensate at low temperature in constrast to the hydrogen case. The question has to be seuled by experiments which are underway elsewhere [9]. To begin with we consider, therefore, a frozen $T_{2}$-source for which final state effects seem to be calculable with sufficien: precision [10].

\section{Principle of a solenoid retardation spectrometer}

With the source placed in the centre of a solenoid, a decay clectron will spiral into the low field region along and around the particular field line at which it was born (compare Fig. 1). On its path into low field, the electron will be accelerated axially on cost of the transverse energy of its cyclotron motion. In case of adiabatic motion (i.e.. the relative change of the magnetic field during one cyclotron period is every. where much smaller than 1), the transverse kinetic energy is reduced by the same factor by which the field has dropped:

$E_{\mathrm{i}}^{\perp} / E_{0}^{\perp}=B_{1} / B_{0}$.

Let us assume the ratio $B_{1} / B_{0}=10^{\prime} \mathrm{T} / 9 \mathrm{~T}$, then the maximum possible value of $E_{i}$ would be $2 \mathrm{eV}$ for an electron starting with a cotal energy of $18 \mathrm{keV}$ at $B_{0}$. Assuming $B_{1}$ being a homogencous field, furthermore, one could retard the electrons in an eleciric field of a double condenser, formed by
3 parallel grids, e.g., Setting the central grid at the potential $U$, all electrons with a parallel kinetic energy $E_{i}>$ eU would pass the grid. They would then be re-acceleratcd in the second hatf of the condenser and be refocussed on a delector by a second solenoid (see Fig. 1). Since $E_{1}$ differs from the 1olat starting energy $E_{1}+E_{0}^{+}$by no more than $2 \mathrm{eV}$ for any direction of decay into the forward hemisphere, the transmission of the electrostatic filter would drop from 1 to 0 within that energy interval.

It thus combines the advantages of very high resolution and optinum transmission. Its inlegral way of functioning would nol be disturbing, really, since one would operate it anyhow close to the endpoint only where the uninteresting low encrgy part of the spectrum is rejected.

However, a design as sketched in Fig. I contains some serious dangers and drawbacks:

(1) The grids and, in particular, the central electrode represent an uncalculable and probably faial source of background. Because electrons emerging from these grids by the decay of any adsorbed tritium contamination or by secandary emission due to cosmics will reach the detector unfiltered. Therefore, the magnelic flux tube within which the electrons are iransported from the source to the detector should not contain any maller and should be kepl al ultrahigh vacuum. On the other hand, this solenoidal transport system protects the detector from any background electrons originating from somewhere outside the flux tube (e.g.. from the walls of the vacuum (ank), since these electrons will spiral along a field line by-passing the detector area. This is an advantage over conventional. purely electrostatic filters.

(2) If the electrons were guided at full energy into the low field region, their spiral molion would stretch oul 10 an almost straight line. Consequently the adiabaticily cricerium could he fulfilled only al very small magnetic field gradients. requiring an enormous length of the apparatus.

It is preferable, therefore, to decelarate electrostatically the logitudinal motion already in the transition region from high to low $B$-field such that the longitudinal acceleration by the magnetic field gradient is just compensated. In order not 


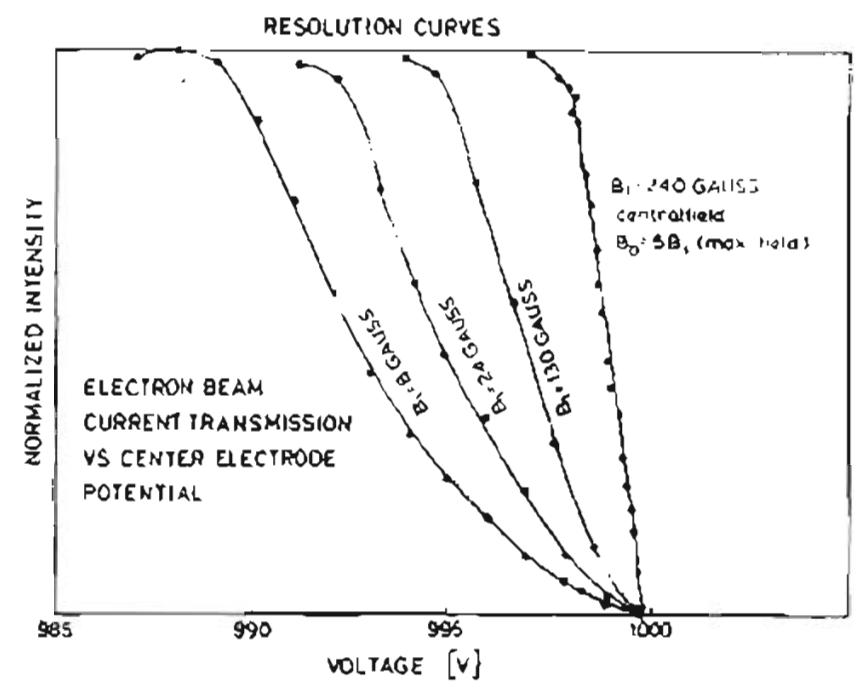

Fig. 2. Transmission function of an I keV lesi spactrometer, measured as a funclion of the cential guiding field $b_{1}[1 I]$

10 deflect the electrons, the $E$-lines should in principle be always parallel to the $B$-lines. But this condition is relaxed considerably by the slabilizing accion of the (much stronger) Lorentz force which limis the side drift of the electron to stay within the diametcr of the well-known roselte of magnetron motion. This effect has been demonstrated recently in a pilor experiment, where a $1 \mathrm{keV}$ electron beam passed an electrostatic filler. It consisted of a series of ring electrodes with the maximum potential on the central one. Parallel to the beam axis an inhomogeneous magnetic field was applied which decreased by a faclor five on the way from the electron source to the central electrode in order 10 parallize the electron beam. Figure 2 shows the filter transmission as a function of the central potential for different values of the magnetic field strength (measured at its minımum value in the centre). One observes that the half width decreases from about 5 to leV by increasing the field from $810240 \mathrm{G}$ [II]. The electron behaves just like a bullet - so to say - the path of which is the sulfer the faster it spins. It can be shown, moreover, that in a magnetic monopole field the electron motion is striclly adiabaric in the sense of eq. (4), irrespective
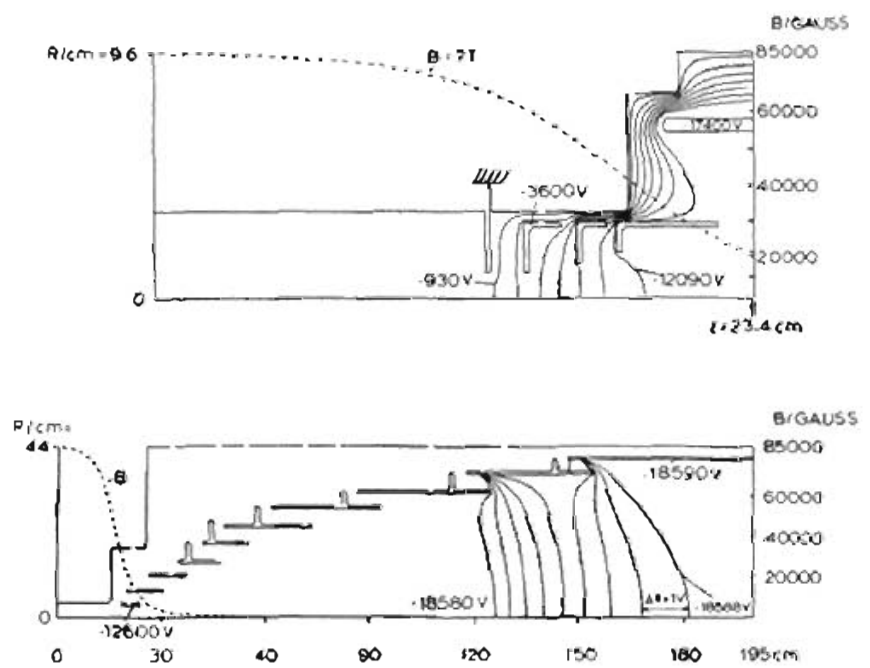

Fig. 3. Configuration of electrodes and fields of the solenord retardation speciromelce under consiruclion. Further explanations in the texl. Dimencions are given on the - and 2-axis: on the right ordinace also the seale of the $B$. ficld on the 2-axis (dushed curve) of the large gradient $\left(\sim 1 ; r^{3}\right)$ of such a field [12]. A magnetic monopole field is realized approximately around the front end of a solenoid. The corresponding elecinc monopole field for longiludinal deceleration can be generated by a series of ring electrodes whose diameler and potential increase outwards.

Figure 3 shows the arrangement of electrodes. In the upper part are the front electrodes, facing the solenoid, in the lower one the central elcctrodes where the repelling potentral attains its maximum value. Shown is only a cross section through the upper lefi sector of the spectromeleer which observes cylindrical symmetry around the z-axis and mirror symmetry with respect to its cencral plane at $z=195 \mathrm{~cm}$. The dashed line gives the magnelic field strength on the $z$-axis as produced by the two solenoids placed at both ends of the spectrometer. One contains the source, the other the detector

The decisive equipotential lines ncar the center of the spectrometer are plotted with a spacing of I $V$ in the lower right part of Fig 3. They prove thal the variation of the maxinum potentiai (18000 V) in the symmetry plane (i.e., the central potenial hole) is of the order of $1 \mathrm{eV}$ only thus enabling a very high resolution over the full plane of the spectrometer This high constancy of the central potental is achieved by virtue of this special design which keeps the fron: electrodes (bcing dangerous because of its very difierent potential) small and well-shielded by the intermediate ones.

We conclude this section by prescnting some results of numerical calculations of paricle irajectories performed wilh the well-known Hermannsfeld program [13]. l1 was modified, however, in order 10 facilitate the Rungc-Kulla inlegration of the lrajectory which has an extremely strong curvalure in a fixed coordinate system due to the large Lorentz force. This requires a ver, large number of integration sleps. If uns advisable. therefore, to integrate the equation of motion in an accompanying cylindrical coordinate irame which is aligned everywhere 10 th particular magnetic field line around which the electron spirals. In this system the asimuth $[\varphi(z)]$ and the radius $[r(z)]$ of the (rajectory vary only smoothly with the propagation along the actual $z$-axis (14).

Figure 4 shows the check of the adiabatic transformalion of transverse energy according eq. (4) along a t)pical trajec-

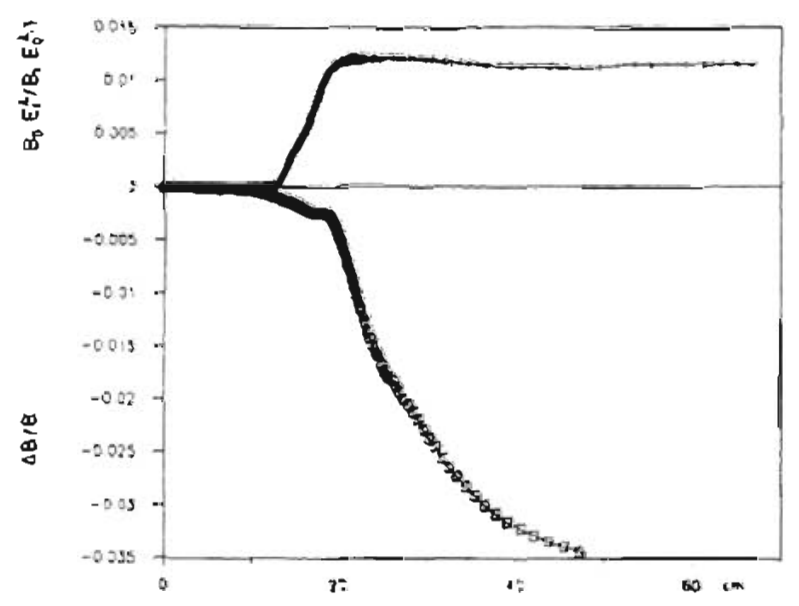

Fig. 4. Numerical chock of adiabacily. Lower curve. Relalive change of magnetic field $\triangle B / B$ per cyclotron period. Upper curve: Violation of adiabacity as measured by the function $B_{0} / B_{1}, .1 C_{\text {; }}-\mathrm{I}$. Beyond $z=60 \mathrm{~cm}$ it levels off. With respect $10 E_{1}^{\prime}$ l comesponds to a deviation of $\Delta E^{L} \sim 0.1 \vee$ al the righl end of the diagram 


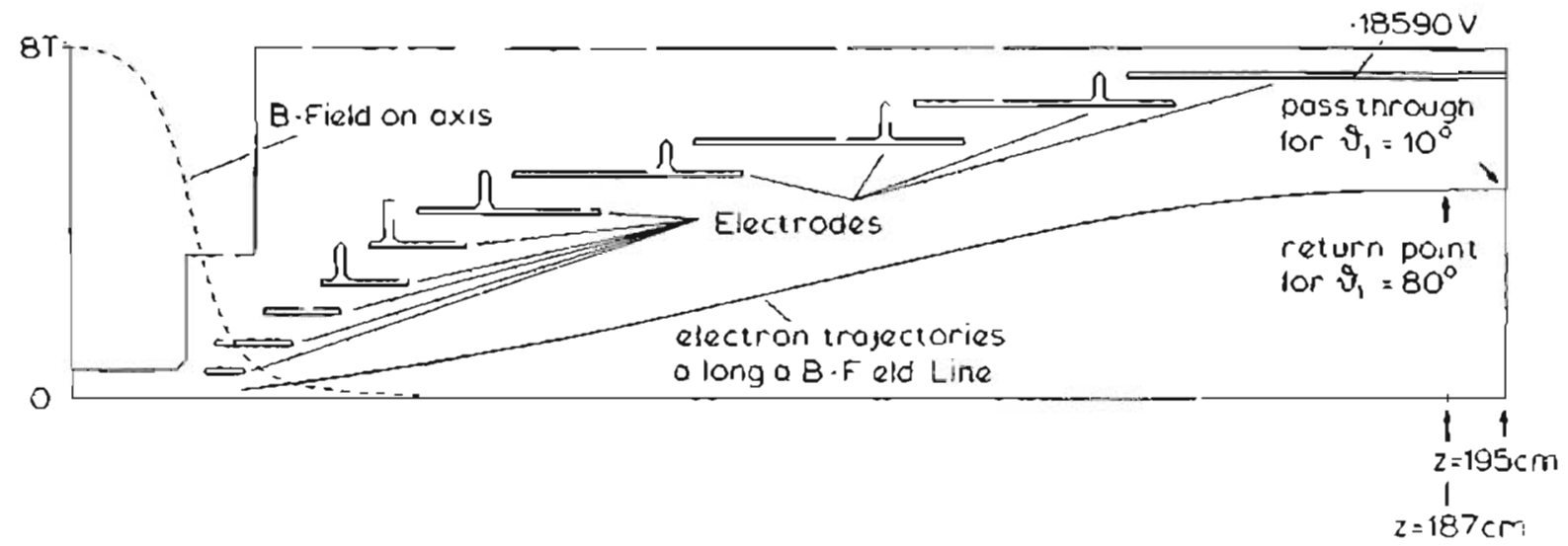

Fig. 5. Two critical electron trajectories. bolh starting off axıs with a total energy $E_{0}$ being $\sim 1 \mathrm{eV}$ above the central potential barner at $z=197 \mathrm{~cm}$. Thc onc starting with polar angle $9=10^{\circ}$ passes the barrier. the one starting with $\$=80^{\circ}$ is rellected at $==187 \mathrm{~cm}$. a fraction of a Volt below the maximum of the barrier.

1ory through the field configuration of Fig. 3. One remarks thal the violation of eq. (4) never exceeds a few percent which is quite satisfactory. Thus the calculation insures that the spectrometer will inded reach the proposed steep trans. miscion function which drops from I to 0 within an energy range of

$\Delta E \sim E_{1}^{1} \sim E_{0} B_{1} / B_{0}$

which is about $10^{-4} E_{0}$ for the field configuration considered. This is furcher demonstrated by the two calculated trajectories shown in Fig. 5. In bolh cases the electron starts with the same total energy $E_{0}$ chosen about l $\mathrm{eV}$ above the filter potential. The one, emitted with a polar angle $\vartheta=80^{\circ}$, is reflected just before the symmetry plane at a potential of about $0.5 \mathrm{~V}$ below the maximum one, whereas the one starting with $\theta=10^{\circ}$ passes the filter.

\section{Status of the experiment}

The design of the spectrometer has been finished early in 1987. The spectrometer tank and the superconducting solenoids have been delivered this summer. The whole set-up including a solid $T_{2}$-target, containing about $10^{16} T_{2}$ atoms, and a suitable detector are expected to be ready for running by the end of this ycar.

\section{References}

I. Boris. S. el al, Phys. Rev, Let1. 58. 2019 (1987)

2. Kündig. W. el al.. Phys. Lell, B173. 485 (1986).

3. Wilkerson. J. F. ef ol., Phys. Rev. Lel1. 58. 2023 (1987).

4. Walraven, J. T. M. el ol. Phys Rev. Lett, 45. 449 (1980).

5. Kleppner. D. el al., Phys. Rev. Lelt. 47. 1195 (198I).

6. Lobashev, V. M. es al. Nucl. Insir. Meth. A240, 105 (1985).

7. Greylak. T. J. and Kleppner, D., in New Trends in Alomic Physics. p. 1125 (Edited by S. Gryoberg and R. Siora), Les Houches Session XXXVIII 1982 (1984).

8. Silvera. I. F. and Walraven. J. T. M., in Progress in Low Teroperalure Physics. Vol. X, North Holkand, Amsierdam, in prin1.

9. Hardy. W. N. el al. Privalc communication.

10. Fackler. O, el al. Phys. Rev. Lell. 55. I 388 (1985).

1I. Moore. R. B. Privale communication.

12. Lehner. B.. Dynamics of Charged Parlicles. Amsicrdam (1964;

13. Description of the Program in Electron Trajoctory Program. W. B. Hermannsicldt. SLAC Rcport-226. Nov. (1979).

14. Description of the Allered Ray Traceing Routine, in Diplomarteit. Th. Edling. Insciruc für Physik der Univessità Mainz (1987). 